\title{
Research and Practice on the Flipped Classroom Teaching Mode in "Microcomputer Principle and Interface Technology" Course Based on the Micro Learning Resources
}

\author{
Ningning Zhou and Yulong Deng
}

\begin{abstract}
Network teaching resources play a crucial role in the flipped classroom teaching model. The micro learning resource is a new type of network teaching resources, which has great application potential in the teaching. With the guidance of constructivism, according to the characteristics of specific curriculum, this paper organized and designed the micro learning resources based on the constructivism theory. Then it studied and designed the teaching links of the flipped classroom. Finally, combining with the specific application environment of the curriculum, it integrated the micro learning resources and flipped classroom teaching mode and applied to the teaching practice of "Microcomputer Principle and interface technology" course. Practice result shows that the novel teaching model is practical and operational, and it has a significant effect on improving students' learning initiative, enthusiasm and learning effect.
\end{abstract}

Index Terms-Micro learning resources, flipped classroom, constructivism, microcomputer principle and interface technology.

\section{INTRODUCTION}

At present, the classroom teaching in universities is mainly based on the traditional way that the students listen to the teacher. In the traditional classroom teaching mode, the teacher is the core and the students learn knowledge passively and are lack of learning initiative and interest, which results in the limited teaching effect. Especially for the theoretical and practical course "Microcomputer Principle and Interface Technology", the students generally feel that it is difficult to learn and understand. Furthermore, they think the concepts in this course are abstract and lack of perceptual knowledge, which makes them lose their interest in learning [1]. As a teacher who has been teaching this course for more than 20 years, in order to improve students' learning interest and initiative, and improve the actual teaching effect, I have been always studying the teaching model which is suitable for this course.

Among the teaching modes, flip the classroom which takes the students as the core of the classroom, and upgrades the teacher to the designer of students' learning has become a research hotspot in the field of educational technology [2], [3]. Different from the traditional classroom teaching mode, the

Manuscript received March 19, 2017; revised May 21, 2017. This work was supported by the Nanjing University of Posts and Telecommunications under Education reform project JG00415JX57

The authors are with the School of Computer, Nanjing University of Posts and Telecommunications, Nanjing, China (e-mail: zhounn@ @jupt.edu.cn, dyl@njupt.edu.cn). teacher's responsibility is to understand the students' problems and guide the students to use the knowledge in the flipped classroom teaching mode. The students can find and learn from high-quality teaching resources on the Internet, which makes them no longer simply to rely on the teacher. In this model, the students and the teachers will benefit from each other. Thus, the initiative and enthusiasm of the students will be greatly improved. Undoubtedly the network teaching resources plays a vital role in the classroom teaching model. Among them, the micro learning resource is a new developing network teaching resources [4]. With the development of micro learning as well as "open class video" and "Massive Open Online Course"( MOOCs) [5], more and more attentions has been paid to micro learning resources in our educational circles. Micro learning resources not only brings us a new organization of teaching resources, but also demonstrates us a new teaching philosophy, teaching ideas and teaching methods. Moreover, it also generates the MOOCs learning environment with micro learning resources as a unit. Integrating the micro learning resources into the flipped classroom teaching has become the research focus of educational scholars. According to the characteristics of the compulsory course "Microcomputer Principle and Interface Technology", this paper organized and constructed the micro learning resources based on the constructivism theory, and studied and designed the teaching links of the flipped classroom. Practice result shows that the novel teaching model is practical and operational, and it has a significant effect on improving students' learning initiative, enthusiasm and learning effect.

\section{MiCRO LEARNING RESOURCES ORGANIZATION AND CONSTRUCTION BASED ON THE CONSTRUCTIVISM THEORY}

Micro learning resources is a kind of new teaching resources. The core content of the micro learning resources is the classroom teaching videos. Besides, it also includes some supplementary teaching resources such as: the teaching design, teaching material related to the subject of the courseware, teaching reflection, practice test, feedback from students, teachers' comments and so on. By a certain organizational relationship and presentation, these resources create a semi-structured, thematic resource unit application "small environment". Therefore, the micro learning resources is different from the traditional single resource. It is a kind of new teaching resources which inherits and develops from the traditional resources. This paper firstly analyzed the characteristics of the "Microcomputer Principle and Interface 
Technology" course. Then organized and designed the micro learning resources with the main characteristics of self constructing knowledge based on the constructivism theory.

\section{A. The Constructivism Theory}

Constructivism [6]-[8] is a branch of cognitive psychology. Its idea comes from the theory of cognitive processing, as well as Viggo $\mathrm{J} \mathrm{Ki}$, Piaget and Bruner's thoughts. Constructivist learning theory holds that the learning process is not the process that learners passively accept knowledge, but the process that learners actively construct knowledge. The constructivist learning activity is learner centered, and it is real. So learners have more interest and motivation, which can encourage learners to do the critical thinking and be easy to provide individual learning styles.

The core of micro learning resources is that the teacher is the disseminator of knowledge and the students are the main part of the cognitive process and the active constructor of knowledge meaning. Therefore, the micro learning resources can not only reflect students-centered teaching conception but also reflect student's main body status which let students experience the charm of inquiry and the joy of success. As a result, the teaching process of micro learning resources should be designed and developed from the perspective of "learning" for the students. We should always focus on what the students learn, guide the students how to learn and pay attention to the learning effect.

\section{B. Micro Learning Resources Organization and Construction}

The "Microcomputer Principle and Interface Technology" course includes two main parts: assembly language programming and interface technology. In this course learning, software learning and hardware learning cannot be isolated. We should let students realize that the software learning and hardware learning are closely related. The software design depends on the hardware circuit, and the hardware circuit works under the control of the software. During the teaching of the whole course, we apply the teaching method that combines the examples and experiments and emphasize the co-design method of hardware and software.

When construct the content of micro teaching resources of the "Microcomputer Principle and Interface Technology" course, firstly we should choose some independent topics according to the characteristics of the two different parts. Point cuts of these topics are small but targeted which can reflect the difficulty and focus of the course and are suitable for multimedia expression. For the part of assembly language programming, we select such as the assembly instruction execution process, addressing mode, typical assembly instructions, and typical code conversion programs design and so on as the topics. While for the part of computer interface, we choose such as the typical bus standard, features and hardware structures of different ways which complete information exchange between computer system and peripherals devices, operation principle and I/O programming of typical interfaces, and design and implementation of some comprehensive experiments and so on as the themes.

Secondly we should focus on how to design and organize the micro teaching resources on the related topics. The content of micro teaching resources should be fine and emphasizes detail. According to the different theme, we should apply different multimedia means to express. Simple and vivid interpretation of knowledge is used to improve students' learning interest about the related content by micro teaching resources. Take the execution process of assembly instruction as an example. Though the execution process of assembly instruction, we need to introduce the function of each part of CPU and the basic structure of each programming visible register in real model. Furthermore, we must pay special attention to emphasize the concepts of the logical address, the physical address and the effective address. The relationship among these addresses is also very important. The difficulty in the designing micro teaching resources is to decide an appropriate means to express the knowledge according to the characteristic of different theme. For example, when design the micro courseware about addressing mode, the question method can be used. Through the special questions of the knowledge points, presentation of the knowledge is different from the classroom teaching. The questions which are layers of progressive are conductive to the development of students' thinking space. First of all, it must be clear that the main function of addressing mode is how to find the operands. The steps of micro teaching resources design related to addressing mode are as follows 1): Design some related question. What kinds of operands are there in the micro computer system? How to find each kind of operand? There are seven kinds of addressing modes to be used to find the operands. For example, register name is used to distinguish every register operand while the physical address is used to locate the every memory unit. Then, the problem is how to represent these different kinds of operands in assembly language? 2) According to the characteristic of each addressing mode, design the corresponding animation to demonstrate the processes of the seven different addressing modes. 3) Summarize the characteristics of each addressing mode. Through the study of micro courseware, the content of this topic is deepened and the difficulties are broken. Another example, when design the micro courseware about the hardware structures of different ways that exchange the information between the micro computer system and the peripherals devices, the date stream method is selected. According to the direction of data stream, it focuses on how these chips work in the process of data transfer between CPU and peripherals devices. On the one hand from the view of CPU, analyzes how to interact the data between the CPU and interface. On the other hand from the view of peripheral devices, discusses the data exchange process between the interface and the device. By organic combination of these two aspects, students will be able to understand deeply that the interface is the information exchange station between CPU and peripheral devices and also be impressed by the data input / output process.

The construction of micro teaching resource is only the first step of flipped classroom teaching mode. Professor Clark, a famous professor of education, has ever said "It is the teaching design, rather than the medium of teaching, to determine the learner's learning." As a result, after constructed the micro teaching resources related to some topic based on the constructivism thoughts, it is need to carry 
on the thorough research to the main teaching links and to discuss the implementation process of teaching in flipped classroom based on the micro teaching resources.

\section{IMPLEMENTATION PROCESS OF FLIPPED CLASSROOM}

\section{A. The Flipped Classroom Teaching Mode Based on Micro Teaching Resources}

Micro teaching resources has great potential applications in teaching. It is not only a teaching resource which can be used by teacher in classroom, but also a studying resource which can be used by the students at home. Make full use of its characteristics of online learning, combined with the flipped classroom teaching model, micro teaching resources changes the way which teachers organize the classroom teaching. In this teaching mode, firstly, the students are asked to watch the micro teaching resources video by themselves before class. Secondly, the students will discuss the related topic and communicate with the teacher in the classroom. At last, the students need to do some exercise and homework after the class. This teaching mode makes the students to find a sense of existence in the classroom. During the studying activity, the students become more active from passive which results in a strong enthusiasm for independent learning and inquiry. This also increases the interaction and personalized communication between the students and teacher. Jonathan Berman and Aaron Sams pointed out that the flipped classroom is not another name of online video. Besides the teaching videos, there is face-to-face interaction time which the students and the teacher carry out meaningful learning activities in the flipped classroom teaching mode. Video cannot replace teachers, nor can it simply be regarded as an online course. The students do not learn in isolation or in disorder.

According to the main teaching links, the flipped classroom teaching mode based on micro teaching resources is designed as shown in Fig. 1.

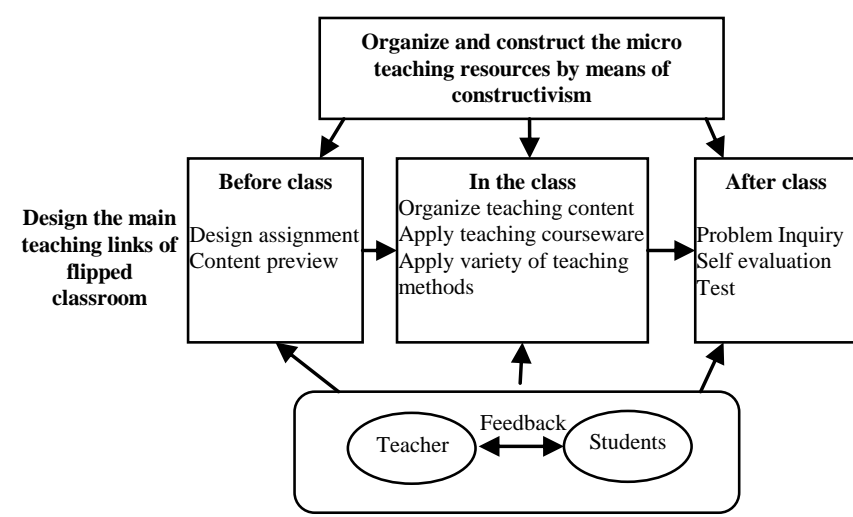

Fig. 1. The flipped classroom teaching mode based on micro teaching resources.

\section{B. Implementation Progress of Main Teaching Links}

In the flipped classroom teaching mode, the micro teaching resources is applied to the following main teaching links:

The "before class" teaching stage of flipped classroom is the preview stage. The teacher designs questions which are helpful for the students to think and discuss and guides students to watch the micro teaching resources which reflect the key points and difficulties of the course in advance. In this stage, the teacher encourages the students to try their best to acquire knowledge and discover problems. At the same time, the students can communicate with and feedback to the teachers on the social network media (WeChat group, QQ group), and the teacher answers the personal problems. According to the common problems, the teacher adjusts teaching contents and teaching methods. Moreover the teacher makes the common problems to form some topics which are regarded as the important contents to analyze and discuss in the classroom teaching. For example, in "Microcomputer Principle and Interface Technology" course, by watching the micro teaching video, the first difficulty for the students is that they always confuse the memory unit with the register. When the teacher gets the feedback from the students, he will focus on the different between the memory unit and the register during the class. Furthermore, the teacher explains the addressing mode for these two operands in detail, especially for the addressing expression for memory unit in assembly language. By drawing inferences about other cases from one instance, it strengthens the students' understanding of the content.

During the "in class" stage of flipped classroom teaching, the teacher combines the micro resources, micro exercises, micro tests, micro evaluation and micro feedback to form the effective control of the students' learning process. According to the feedback of the preview stage, the teacher organizes the teaching content and designs several teaching methods. In accordance with the feedback of the students in the classroom, the teacher cites large number of examples to explain these problems by means of combining the blackboard and multimedia. Then carry out the collaborative learning by the way of group cooperation. The students discuss and communicate the content of the course with each other in the group. The method of grouping is often changed and random which reduces the influence of the fixed group on the students as far as possible and let each student has the opportunity to perform, and perform visibly in each semester. The Teacher can also find some problems in the discussion, and performs personalized counseling. A variety of ways to discuss and communicate are applied during the class. For example, select a student from the group to take the role of the teacher which explains the knowledge to other students and answers the students' questions on the spot. Sometimes some games such as contest, preemption answer, and challenge match and so on are organized during the class to improve the initiative of the students learning. These measures encourage the students to spend more time on studying. All the students at different levels benefit from it. This highly independent, personalized and creative learning is far beyond the classroom itself.

The "after class" teaching stage of flipped classroom is the "problem inquiry" link. During this link, the teacher asks the students to conduct a more in-depth inquiry on certain topic or question to extend the depth and breadth of the students' concept and knowledge learning. At the same time, the teacher designs some more open questions to encourage students to search the solutions in the network which expands the boundary of inquiry of students' knowledge. Besides some regular homework, the students are asked to design a 
periodical examination paper at the end of each learning stage. According to the feedback of the homework and the result of the test, the teacher knows the situation of the students to grasp the knowledge in real time. Sometimes, the teacher needs to perform remedial teaching for certain teaching content. Furthermore, the teacher analyzes the problems and causes of students' learning and adjusts the content and process of the next class.

\section{Practice Teaching EfFect Analysis}

In order to evaluate the teaching effect of the new teaching model, practice this flipped classroom teaching mode base on micro resources to the course "Microcomputer Principle and interface technology" in intensive class of Baier College in Nanjing University of Posts and Telecommunications, China. From the results of the students to complete the task, the teaching mode has made great achievements. By the flipped classroom teaching based on micro resources, the students' enthusiasm and independence have been improved. Before class, the students previewed and discussed the knowledge points related to the several problems pre-arranged by the teacher. In the class, students were actively thinking and speaking and were willing to share the understanding of knowledge with the others. In particular, in classroom discussion and the classroom flipping, the students changed from the feeling little nervous at the beginning to positively showing in later. The students' enthusiasm for learning this course has been improved. After class, students did the homework consciously and conscientiously. Moreover they could understand and correct errors in the homework in time. They took each experiment seriously and summarized the experimental process and results. As a result, they all got good mark in the final exam. By contrast, the students' initiative and enthusiasm in learning and the proportion of students who think actively in class of traditional teaching mode are significantly lower than that of in the flipped classroom teaching mode based on micro resources. A comparative analysis of the students' interest in the course and the final results of the two classes teaching modes are shown in Table I and Table II.

TABLE I: DEGREE OF INTEREST FOR THIS COURSE

\begin{tabular}{lccc}
\hline \hline Teaching mode & High & Medium & Low \\
\hline New teaching mode & $70 \%$ & $20 \%$ & $10 \%$ \\
Classic teaching mode & $30 \%$ & $50 \%$ & $20 \%$ \\
\hline \hline
\end{tabular}

TABLE II: SCORE DISTRIBUTION OF FINAL EXAM

\begin{tabular}{lllll}
\hline \hline Teaching mode & $100-90$ & $89-80$ & $79-70$ & $69-60$ \\
\hline New teaching mode & $6.0 \%$ & $36.3 \%$ & $30.3 \%$ & $15.2 \%$ \\
Classic teaching mode & $0.0 \%$ & $33.3 \%$ & $25.0 \%$ & $16.7 \%$ \\
\hline \hline & & & \\
Teaching mode & Failed & Average \\
\cline { 2 - 4 } New teaching mode & $12.1 \%$ & 76 & \\
Classic teaching mode & $25.0 \%$ & 66 &
\end{tabular}

As can be seen from Table I there are more than $70 \%$ of the students who are very interested in this course in the new teaching mode, which is much higher than the traditional teaching mode $(30 \%)$. From the final examination results in
Table II, it can be seen clearly that students in the new flipped teaching mode scored significantly higher than that of the traditional model. These results indicated that the flipped classroom teaching mode based on the micro resources under the view of constructivism has practicality and operability which can greatly improve students' learning initiative, enthusiasm and the actual teaching effect.

\section{CONCLUSION}

At present, the development of micro teaching resources meets the emergence of global Massive Open Online Course which makes it mixed with Massive Open online education quickly and widely. Deep integration of information technology and teaching is the key and difficult point in the reform of education and teaching in China. One of the best entry points to realize the goal of the deep integration is to incorporate the micro teaching resources into the flipped classroom teaching mode. According to the characteristics of the certain course, this paper applies the method of constructivism to organize and design the micro teaching resources. The main teaching links and processes of lipped classroom teaching are also discussed and designed in this paper. Finally, combined with the specific course, it integrates the micro teaching resources into the flipped classroom teaching mode. Students' autonomous learning ability, initiative and enthusiasm have been greatly improved in this kind of teaching mode.

\section{REFERENCES}

[1] N. Zhou, W. Wang, and W. Cheng, "Research on teaching mode of microcomputer principles and interface based on constructivism," Experiment Science and Technology (China), vol. 9, pp. 117-119, April 2011.

[2] R. Hu and B. H. Zhang, "Flipped classroom and flipped learning: Analyze the efficacy of Flipping," Journal of Distant Education (China), vol. 34, pp. 52-58, April 2016.

[3] K. K. He. "The future development of "flipped classroom" in China from the essence of flipped classroom," e-Education Research (China), pp. 5-16, July 2014.

[4] Y. C. Zhang and Y. Y. Qian, "The resource construction of micro lecture at home and abroad and its latest application development," Journal of distant education (China), pp. 26-33, June 2013.

[5] T. S. Hu and X. Q. Zhou, "Current situation analysis and development strategies of the micro-lecture construction in universities," Modern Educational Technology (China), vol. 24, pp. 5-13, February 2014.

[6] K. K. He, "Constructivism: The theoretical basis for the reform of traditional teaching (Three)," Journal of Educational Studies (China), pp. 12-16, April 1998.

[7] F. Khan. "Constructivism as a paradigm for teaching and learning," International Journal of Psychology \& Counseling, 2013.

[8] T. Cetin and D. Engin, "The effect of constructivism on attitudes towards lessons: A meta-analysis study," Eurasian Journal of Educational Research, vol. 62, pp. 1-28,2016

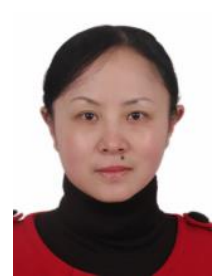

Ningning Zhou was born in Nanjing, China in 1972 She got the doctor degree of instruments and machinery at the South East university, Nanjing, Jiangsu, P.R.China in 2009. Her major field of study is instruments and computer application.

She is currently an associate professor at School of Computer, Nanjing University of Posts and Telecommunications (NUPT), China. She holds the position of guest professor at State Key Laboratory of Software Development Environment in China. Her work in computer science has contributed three books, over 30 papers. Her current research interests include computer application, image processing and virtual reality. 
Dr. Zhou is the associate editor of the "International Journal of Intelligent Autonomous Systems (IJIAS)" and the reviewer of the international journal "Knowledge-based systems". She is a member of China Computer Federation.

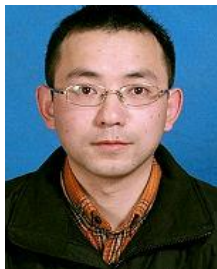

Yulong Deng was born in Guizhou, China in 1975. He got the master degree of computer software and theories at Nanjing Univ. Of Posts and Telecommunications, Nanjing, Jiangsu, P.R.China in 2010.

$\mathrm{He}$ works currently as a lecturer at School of Computer Science, Nanjing University of Posts and Telecommunications and his research interest is information network.
Mr. Deng is a member of China Computer Federation. 